\title{
Utilização e percepção de usuários sobre aplicativos digitais criativos: otimização da atividade por meio da tecnologia
}

User manipulation and perception on digital creative applications: optimization through technology

\section{Alex Lustosa Silva}

Universidade Estadual de Londrina

alexlustosasilva@gmail.com $\mathbf{x}$

Vanessa Tavares de Oliveira Barros

Universidade Estadual de Londrina

tavaresdebarros.vanessa@gmail.com $\mathbf{x}$

\section{PROJËTICA}

\section{COMO CITAR ESTE ARTIGO:}

SILVA, A. L.; BARROS, V. T. O. Utilização e percepção de usuários sobre aplicativos digitais criativos: otimização da atividade por meio da tecnologia. Projética, Londrina, v. 11, n. 1, p 37-59, 2020.

DOI: 10.5433/2236-2207.2020v11n1p37

Submissão: 24-04-2017

Aceite: $30-05-2019$

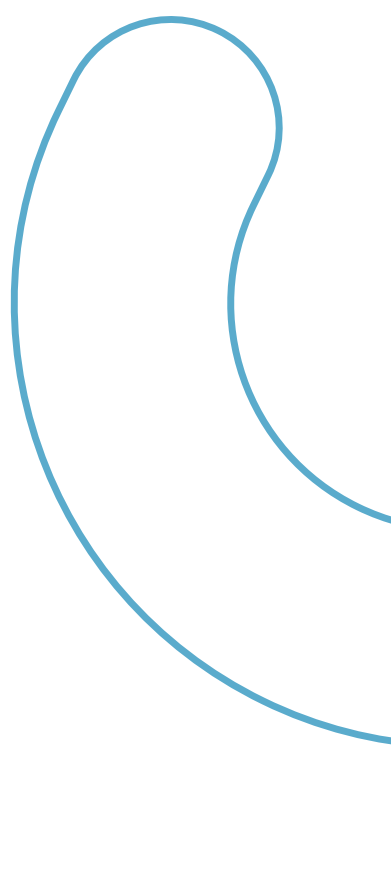


Projética, Londrina, v.11, n.1, p. 37-59, abril 2020

RESUMO: Este artigo discute processos criativos e o conceito de criatividade a partir da utilização de aplicativos digitais. Tem como objetivo descrever a influência desta utilização em atividades criativas, considerando a percepção de usuários e os aspectos funcionais de cada aplicativo. Para tanto, utilizou-se de pesquisa exploratória a fim de verificar quais aplicativos estão relacionados à criatividade, bem com as percepções de seus usuários por meio dos feedbacks de cada aplicativo. Os resultados reforçam as múltiplas perspectivas do conceito de criatividade no universo digital, bem como a utilização destes recursos para a otimização de atividades cotidianas de seus usuários.

Palavras-chave: Criatividade. Aplicativo digital. Usuário.

ABSTRACT: This paper discusses creative processes and the concept of creativity from the use of digital applications. It aims to describe the influence of such use on creative activities, considering the perception of users and the functional aspects of each application. To do so, we used the exploratory research to verify which applications are related to creativity, as well as the user perception through their feedback on each application. Results reinforce the multiple perspectives on the concept of creativity in the digital universe, as well as the use of such resources to optimize users' daily activities.

Keywords: Creativity. Digital application. User.in museums.

\section{INTRODUÇÃO}

O desenvolvimento da sociedade tecnológica fornece paradoxos que situam o sujeito em uma posição crítica frente à sua necessidade intrínseca de criar, produzir e atribuir sentido à sua existência.

A reestruturação e as novas formas de organização do trabalho em torno de processos criativos pressupõem no imaginário social a ideia de um trabalho 
livre, com menos riscos de exposição aos danos provenientes de rotinas laborais e dinâmicas instituídas em empresas. Esta concepção vem sendo amplamente descrita nos veículos midiáticos, associando à autogestão e o trabalho criativo com autonomia, sustentabilidade e prazer no desenvolvimento da atividade, promovendo assim uma valorização da criatividade enquanto estratégia de "reinvenção" do trabalho formal.

Mais que um conceito abstrato abordado em distintas vertentes, a criatividade figura como elemento central na dinâmica subjetiva do trabalho e torna-se "instrumento" da atividade em tempos de modificações socioeconômicas e crise da sociedade salarial.

Destaca-se que ampla utilização de recursos digitais em favor do trabalho criativo e a virtualização das organizações propuseram novas configurações aos processos produtivos e favoreceram distintas possibilidades de subjetivação ao "fazer" criativo. Na medida em que estes recursos promovem amplificação de ideias e o compartilhamento de referências, reforçam ainda a ideia de criação em rede enquanto tendência da pós-modernidade.

Mediante a popularização do uso de dispositivos móveis (smartphones, tablets, notebooks) o surgimento de aplicativos digitais fez com que estes rapidamente se integrassem a experiência de seus usuários, promovendo a interação entre atividades cotidianas e as múltiplas funções destes aplicativos visando à otimização de diversas atividades. Trata-se, portanto, de uma temática de estudo propícia para a Ergonomia mantendo devido diálogo com perspectivas contempladas por esta, como a Psicologia e o Design de Interfaces.

Uma pesquisa realizada pela Fundação Getúlio Vargas, publicada pela Folha de São Paulo em 15/04/2016, mostrou que o Brasil atingiria o número de 168 milhões de smartphones em uso no mês seguinte, com projeção de 236 milhões 
Projética, Londrina, v.11, n.1, p. 37-59, abril 2020

de aparelhos até o ano de 2018. A pesquisa atribuiu este avanço a questões comportamentais e os novos hábitos da população mais jovem (NÚMERO..., 2016).

Diante deste cenário e tomando como foco os aplicativos digitais constatase a necessidade de investigação sobre a amplitude de tais recursos e suas influências em processos de trabalho e criatividade. Por meio de uma pesquisa exploratória, este estudo objetiva descrever como os aplicativos digitais podem influenciar a atividade criativa a partir da percepção de usuários diante do universo digital.

A fundamentação teórica apresenta interlocuções entre criatividade e trabalho, ao tempo que percorre sentidos atribuídos ao conceito. Apresenta-se o delineamento da pesquisa a partir do método adotado, bem como os resultados obtidos após a análise dos aplicativos contemplados na investigação.

\section{FUNDAMENTAÇÃO TEÓRICA}

\subsection{Trabalho e Criatividade: Múltiplas Perspectivas}

Visando o aprimoramento dos múltiplos processos existentes em uma determinada atividade, a Ergonomia enquanto ciência multidisciplinar promove o agrupamento de técnicas e metodologias que tomam como elemento central o trabalho.

A partir das abordagens físicas, cognitivas e organizacionais as perspectivas ergonômicas contemplam aspectos distintos dos seres humanos. lida (1997, p. 1) enfatiza o estudo destes processos a partir da relação do homem com seu trabalho, sendo a Ergonomia a solução para os problemas advindos desta relação. Compreende-se a Ergonomia enquanto: 


\begin{abstract}
Disciplina científica dedicada à compreensão das interações entre o ser humano e outros elementos de um sistema, e a profissão que implica teorias, princípios, dados e métodos para projeto, de modo a otimizar o bem-estar e o desempenho geral do sistema. Os ergonomistas contribuem para o projeto e a avaliação de tarefas, trabalhos, produtos, ambientes e sistemas, no sentido de torná-los compatíveis com as necessidades e limitações das pessoas. (IEA - 2006). INTERNATIONAL ERGONOMICS ASSOCIATION). (VAN DER LINDEN, 2007, p 23).
\end{abstract}

Já o trabalho criativo pode ser abordado por diversas áreas do conhecimento e em diferentes definições decorrentes de linhas teóricas distintas. As pesquisas demonstram que a criatividade é um processo interdependente de uma gama de fatores os quais envolvem: desenvolvimento humano, aspectos sociais, individuais e ambientais (ALENCAR; FLEITH, 2003).

Nesta perspectiva o processo criativo é tido como presente em todo ser humano e passível de desenvolvimento, sendo o domínio da atividade um fator facilitador para a ocorrência desse processo. Tanto na resolução de um problema quanto na criação de um produto, é necessário haver um conhecimento acerca do assunto e deter os meios para abordá-lo. Alencar e Fleith (2003, p. 16-17) destacam que as "[...] grandes ideias ou produtos originais ocorrem, especialmente, em pessoas que estejam adequadamente preparadas, com amplo domínio dos conhecimentos relativos a uma determinada área ou das técnicas já existentes.".

Ostrower (1978) ao estudar o processo de criação aborda a criatividade não como uma condição rara, mas como processo inerente a condição de ser humano em uma integração com a realidade física e contexto cultural. Assim define o autor:

Criar é, basicamente, formar. É poder dar uma forma a algo novo. Em qualquer que seja o campo da atividade, trata-se, nesse "novo", de novas coerências que se estabelecem para a mente humana, fenômenos relacionados de modo novo e compreendidos e termos 
Projética, Londrina, v.11, n.1, p. 37-59, abril 2020

novos. $\mathrm{O}$ ato criador abrange, portanto, a capacidade de compreender; e esta, por sua vez a de relacionar, ordenar, configurar, significar (OSTROWER, 1978, p. 6).

Um estudo realizado por Torquato, Willerding e Lapolli (2013) utilizando o método da revisão integrativa da literatura buscou identificar temas relacionados à criatividade e inovação. Os resultados, embasados em pesquisas consultadas, apontam a necessidade de ampliação do potencial criativo para o bom desenvolvimento de um processo de inovação. Os autores enfatizam a relevância da criatividade na manutenção da qualidade, eficiência, eficácia em processos, projetos e produtos.

Csikszentmihalyi e Nakamura (2014, p. 280, tradução nossa) afirmam que o comportamento das pessoas criativas é uma resposta para o bem-estar da humanidade, portanto, a compreensão do "ethos criativo" proporcionará a aquisição de um comportamento responsável em detrimento da moralidade que enrijece o desenvolvimento de personalidades criativas.

A criatividade pode ainda ser abordada por um conjunto de habilidades cognitivas, estando intimamente relacionada com os traços de personalidade. "A responsabilidade sentida por pessoas criativas envolve integridade, honestidade e excelência na performance de suas tarefas" (CSIKSZENTMIHALYI; NAKAMURA, 2014, p. 280, tradução nossa).

Alicerce da constituição do homem e de sua rede de significações, a criatividade assinala no psiquismo funções simbólicas na medida em que resulta de experiências subjetivas, adaptativas e compositivas do meio. A continuidade do ato criativo ocorre, pois, o homem, "é ao mesmo tempo produtor e produto, artífice e artifício, criador e criatura". (DE MASI, 2003, p. 30). Dejours e Bégue (2010, p. 41) descrevem que "trabalhar não é apenas produzir, é também produzir-se a si mesmos". 


\subsection{Recursos Digitais e Criatividade}

Na era do conhecimento e da informação, os recursos digitais apresentados por diferentes softwares e popularizados por meio dos dispositivos móveis, tornaram-se aliados no processo de amplificação dos processos criativos. Ao problematizar o reflexo destas tecnologias na cultura e conceber suas influências na cognição humana, Levy (1999, p. 172) descreve que estas "colocam novamente em questão o funcionamento das instituições e os modos habituais de divisão do trabalho".

A princípio utilizados estritamente como instrumentos de comunicação e divertimento, os aplicativos digitais rapidamente aliaram-se ao ser humano em áreas distintas, conforme nos aponta a literatura, na saúde (CAIVANO; FERREIRA; DOMENE, 2014; MORAES; PISA; LOPES, 2004; OLIVEIRA; COSTA, 2012), educação e processos de aprendizagem (CORRADI; VIDOTTI, 2009), (ANDRIOLI; VIEIRA; CAMPOS, 2013) ou mesmo nas chamadas práticas de bem-estar presentes na sociedade (OIKAWA, 2014).

Comportamento socialmente aprendido, característica individual, estímulo do ambiente ou mecanismo inconsciente, é certo que o "potencial criativo" se torna objeto de interesse na medida em que o ser humano passa a interagir diretamente com ambientes virtuais, influenciando diretamente na produção de recursos digitais que viabilizam processos criativos.

Neste sentido, é necessário averiguar como os aplicativos disponíveis no mercado digital refletem conceitos de criatividade aqui apresentados em contraponto ao universo da internet, e ainda permitam investigar a relação subjetiva que estes propiciam aos seus usuários, a partir da usabilidade e interface do serviço. 
Projética, Londrina, v.11, n.1, p. 37-59, abril 2020

\begin{abstract}
A ideia básica de interface sugere uma superfície limítrofe entre dois corpos ou espaços. A interface, no entanto, vai além de uma simples separação; indica a possibilidade de adaptação, de interconexão, de COMUNICAÇÃO entre dois ou mais sistemas, equipamentos, unidades etc. que, de alguma forma, apresentam diferenças ou incompatibilidades funcionais. (COELHO, 2008, p. 208).
\end{abstract}

De acordo com Braga (2015, p. 129.) "Para existir um sistema humanomáquina é necessário que existam ações ligando os elementos tanto do humano quanto da máquina na busca por um objetivo, ou seja, uma tarefa comum que leve esses elementos a interagir". Assim entende-se a comunicação enquanto ponto central no processo de interação entre usuário e a interface digital em busca de um objetivo comum para realização de determinada tarefa. Com base nestes fundamentos teóricos, realizou-se a investigação a partir da aplicação da pesquisa.

\title{
3 METODOLOGIA
}

Este estudo tem como objetivo descrever como a utilização de aplicativos digitais pode influenciar atividades criativas a partir da percepção de seus usuários, considerando ainda os aspectos funcionais.

Estando em acordo com os objetivos propostos, a pesquisa caracteriza-se como exploratória. Nesta perspectiva, Gil (2002, p. 41) descreve que a pesquisa exploratória "tem como objetivo geral o aprimoramento de ideias ou a descoberta de intuições [...] de modo que possibilite a consideração dos mais variados aspectos relativos ao fato estudado".

Para a realização da pesquisa, utilizou-se a plataforma Google Play Store, a loja online de aplicativos criada pelo Google para dispositivos com sistema operacional Android. Em dados divulgados pelo site App Brain, em setembro de 
2016, a Play Store possuía um total de 2,36 milhões de aplicativos disponíveis para download. Em acordo com o mesmo site, suas categorias mais populares são: Educação, Estilo de vida, Entretenimento, Negócios, Personalização, Ferramentas, Livros, Música, Viagens e Puzzle (jogos de quebra cabeças ou enigmas).

Ressalta-se que na Play Store, a palavra criatividade aparece como subcategoria na seção de aplicativos da categoria Família. Observou-se, no entanto, que os resultados nesta busca eram voltados a jogos de desenhos infantis. Deste modo, realizou-se a pesquisa a partir da busca geral dos aplicativos "Criatividade" como palavra chave.

Embora não exista a identificação de critérios utilizados pela plataforma para definição e ordem de resultados das buscas realizadas pelos usuários, possibilitou-se esta verificação a partir de um experimento realizado pelo site Moz em 27/05/2015, (WALZ, 2015) (com tradução do site RankMyApp). Deste modo, os critérios para definir o ranking da loja de aplicativos são:

- Média das avaliações na App Store;

- Volume de avaliações e reviews;

- Contagem de downloads e instalações;

- Desinstalações;

- Estatísticas de uso do aplicativo (o quanto os usuários do aplicativo estão engajados, e com que frequência eles rodam o aplicativo);

- Taxas de crescimento consideradas ao longo do tempo (o quanto a contagem de downloads mudou ao longo do tempo, e como as taxas de hoje se comparam às taxas da semana passada);

- Densidade de palavras-chave na landing page do aplicativo.

Para fins de análise, e considerando o filtro de aplicativos realizado por estes critérios, realizou-se a pesquisa considerando os 05 principais resultados 
Projética, Londrina, v.11, n.1, p. 37-59, abril 2020

entre os obtidos na busca. A Google Play Store oferece a além da função "resenha" (classificação dos aplicativos por estrelas) o espaço "resenha de usuários", que possibilita compartilhar opiniões públicas e experiências sobre os serviços oferecidos. Deste modo, a pesquisa contempla feedbacks de 16 usuários sobre os aplicativos estudados. Ressalta-se que a pesquisa se baseia em resultados secundários da plataforma, e por este motivo, não apresenta descrição do perfil dos usuários que participam das resenhas (faixa etária, profissão, classe socioeconômica, aspectos culturais, entre outros).

Para fins de privacidade dos usuários, os comentários selecionados para este artigo serão apresentados seguindo uma ordem numérica. Os resultados dos aplicativos selecionados foram obtidos com o mapeamento realizado pela própria Play Store (atendendo aos critérios de relevância).

\section{RESULTADOS OBTIDOS}

A partir da busca utilizando Criatividade como palavra-chave foram encontrados 250 aplicativos digitais - divididos em categorias variadas e disponíveis para download de forma gratuita ou paga. Estes resultados podem ser visualizados na Figura 01:

Figura 1 - Resultados obtidos a partir da palavra-chave Criatividade

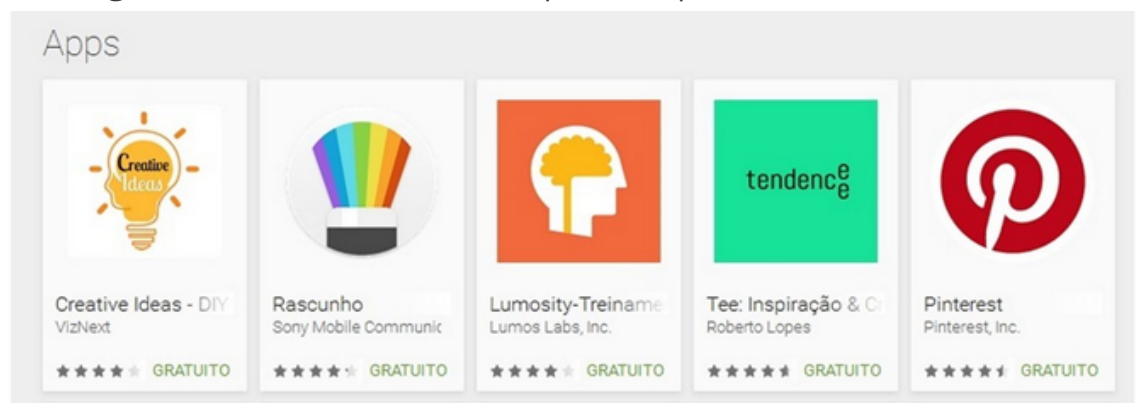

Fonte: Google Play Store 
Observa-se que a própria busca mostra, além da identidade visual dos aplicativos e apresentação das marcas, algumas informações básicas como o nome do desenvolvedor do serviço, custo para download e a uma prévia das avaliações utilizando a classificação com símbolo de estrelas.

A partir da seleção realizada o quadro 01 apresenta um resumo dos aplicativos contemplados neste estudo, bem como algumas informações fornecidas ao usuário que visualiza a apresentação do respectivo aplicativo. A sequência apresentada no quadro segue a ordem da busca apresentada na imagem anterior.

Quadro 1 - Descrição dos resultados da busca a partir da palavra-chave Criatividade

\begin{tabular}{|c|c|c|c|c|}
\hline Aplicativo & Categoria & Custo & Avaliação & Observações \\
\hline $\begin{array}{l}\text { Creative ldeas - } \\
\text { DIY \& Craft }\end{array}$ & Estilo de vida & Gratuito & $\begin{array}{l}3,9 \\
\text { De } 4.463 \\
\text { avaliações }\end{array}$ & $\begin{array}{l}\text { Oferece compras no } a p p \text {, de até } \\
\mathrm{R} \$ 9,49 \text { por item. }\end{array}$ \\
\hline Rascunho & Entretenimento & Gratuito & $\begin{array}{l}4,3 \\
\text { De } 80.925 \\
\text { avaliações }\end{array}$ & $\begin{array}{l}\text { Oferece compras no app, de } \\
\mathrm{R} \$ 2,50 \text { - } \mathrm{R} \$ 7,46 \text { por item. }\end{array}$ \\
\hline $\begin{array}{l}\text { Lumosity - } \\
\text { Treinamento } \\
\text { Cerebral }\end{array}$ & Educação & Gratuito & $\begin{array}{l}4,1 \\
\text { De 162,622 } \\
\text { avaliações }\end{array}$ & $\begin{array}{l}\text { Oferece compras no app de } \\
\mathrm{R} \$ 2,52 \text { - } \mathrm{R} \$ 210,77 \text { por item. }\end{array}$ \\
\hline $\begin{array}{l}\text { Tee: Inspiração } \\
\text { \& Criatividade }\end{array}$ & $\begin{array}{l}\text { Notícias e } \\
\text { Revistas }\end{array}$ & Gratuito & $\begin{array}{l}4,7 \\
\text { De } 14 \\
\text { avaliações }\end{array}$ & Não oferece opções de compras. \\
\hline Pinterest & Social & Gratuito & $\begin{array}{l}4,6 \\
\text { De } 2.165 .089 \\
\text { avaliações }\end{array}$ & Não oferece opções de compras. \\
\hline
\end{tabular}

Fonte: Elaborado pelo próprio autor a partir de dados obtidos na Google Play Store.

A discussão dos resultados obtidos e a análise dos respectivos aplicativos serão realizadas no item a seguir. 


\section{ANÁLISE E DISCUSSÃO}

O primeiro aplicativo localizado na pesquisa, o Creative Ideas - DIY \& Craft (figura 02), possui o layout e descrição de funções semelhantes aos de redes sociais. Assim como o Facebook, o Creative Ideas - DIY \& Craft (figura 02) possui um feed para compartilhamento de publicações e visualização de conteúdos publicados por outros usuários. "Sua ideia tem o poder para impactar o mundo", sugere a descrição do aplicativo.

Figura 2 - Aplicativo Creative Ideas - DIY \& Craft

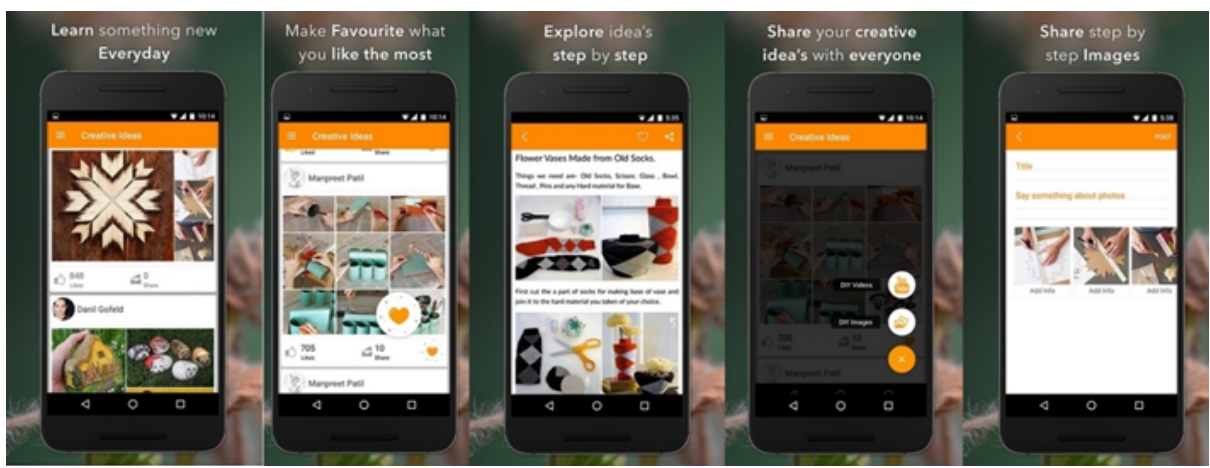

Fonte: Elaborada pelo próprio autor, a partir de busca na Google Play Store.

O Creative Ideas - DIY \& Craft recebe opiniões diversas em relação as suas funções. Estas se mostram associadas a usabilidade para fins pessoais, como descreve o usuário 01: "Muitas ideias criativas e maravilhosas. Eu mesmo já usei algumas delas, claro adaptando ao mesmo uso."

Já o usuário 02 afirma: "Ideias que ajudam o planeta ou sua casa." As opiniões também descrevem a utilização do aplicativo em atividades de trabalho: “Uma ótima ferramenta para buscar inspiração e também para apresentar seus trabalhos." 03. "Muito bom esse app. Ele incentiva pessoas até mesmo abrir seu próprio negócio." ressalta a usuária 04. 
Projética, Londrina, v.11, n.1, p. 37-59, abril 2020

A resenha apresentada pelo usuário 05 define o aplicativo por meio da inovação de sua proposta: "5 estrelas para incentivar. Pois é uma ideia de app muito criativa, de algo que ainda não se vê por aí." As críticas ao Creative Ideas - D/Y \& Craft, referem-se em sua maioria ao fato do aplicativo não possuir versão em português.

O segundo aplicativo, denominado Rascunho (figura 03) é desenvolvido pela Sony. Apresenta funcionalidade de um bloco para rascunhos digitais com recursos de desenhos em lápis, marcadores e pincéis. O app oferece ainda pacotes de adesivos para a edição de fotos. Devido a estas funções, o Rascunho apresenta uma interface mais simples e layout com maior intensidade de cores, com enfoque em um público infantil. “Convide seus amigos para colaborar. Você ficará surpreso com o resultado final da criatividade dos seus amigos", afirma o texto de apresentação do serviço.

As resenhas do Rascunho referem-se à críticas sobre as atualizações do aplicativo (a própria descrição do serviço informa sobre o constante lançamento de pacotes de adesivos) e a inserção ou retirada de algumas funções.

Figura 3 - Aplicativo Rascunho

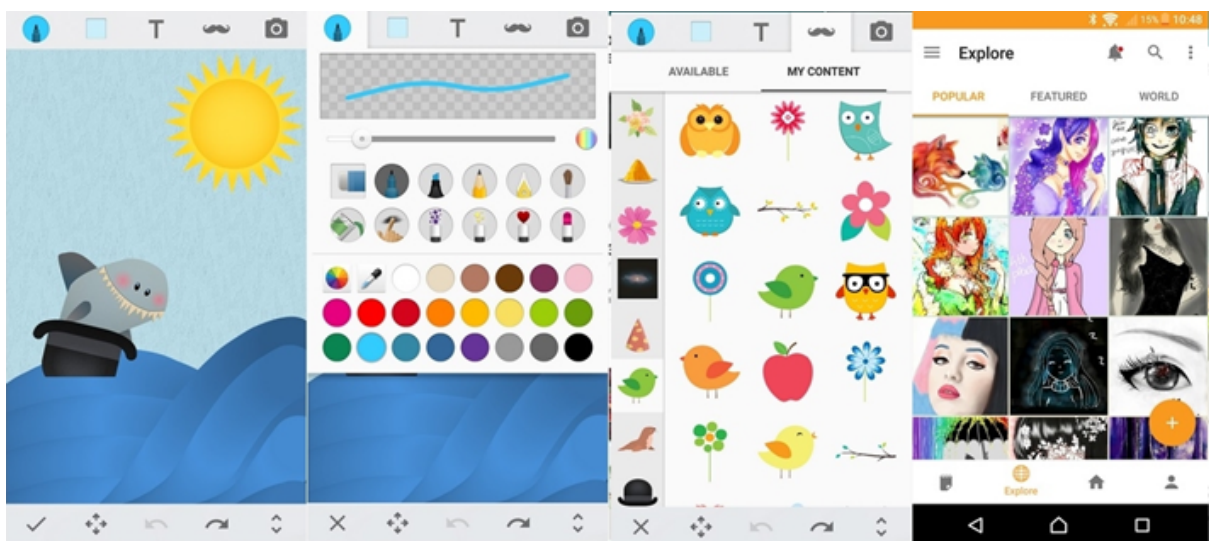

Fonte: Elaborada pelo próprio autor, a partir de busca na Google Play Store. 
O terceiro aplicativo contemplado neste estudo, o Lumosity - Treinamento Cerebral (figura 04), apresenta jogos cognitivos (cerca de 25) desenvolvidos por um time de cientistas - como informa a descrição do serviço: “Nossos cientistas usam tarefas cognitivas e neuropsicológicas comuns ou criam desafios experimentais, totalmente novos. Com a ajuda de designers experientes, essas tarefas são transformadas em jogos divertidos, que desafiam habilidades cognitivas essenciais." O aplicativo ainda promete atualizações a cada duas semanas, a fim de aperfeiçoar a experiência do que define como um "treino cognitivo" e a correção de falhas.

As resenhas de usuários ressaltam a funções prometidas pelo Lumosity Treinamento Cerebral. A usuária 06 afirma: “Desafia minha capacidade todos os dias! Vejo meu desempenho melhorar a cada jogo." As avaliações também associam o aplicativo ao desenvolvimento de valores positivos, como concentração, paciência e inteligência. O usuário 07 descreve: “Ótimo passatempo. Nos dá a oportunidade de treinarmos e desenvolvermos várias habilidades cognitivas." A resenha da usuária 08 descreve a utilização do aplicativo em seu dia a dia: “Melhoras com o tempo. Já faz quase 2 anos que treino praticamente todos os dias. Agora posso verificar com certeza os benefícios de prática diária."

Figura 4 - Lumosity - Treinamento Cerebral.

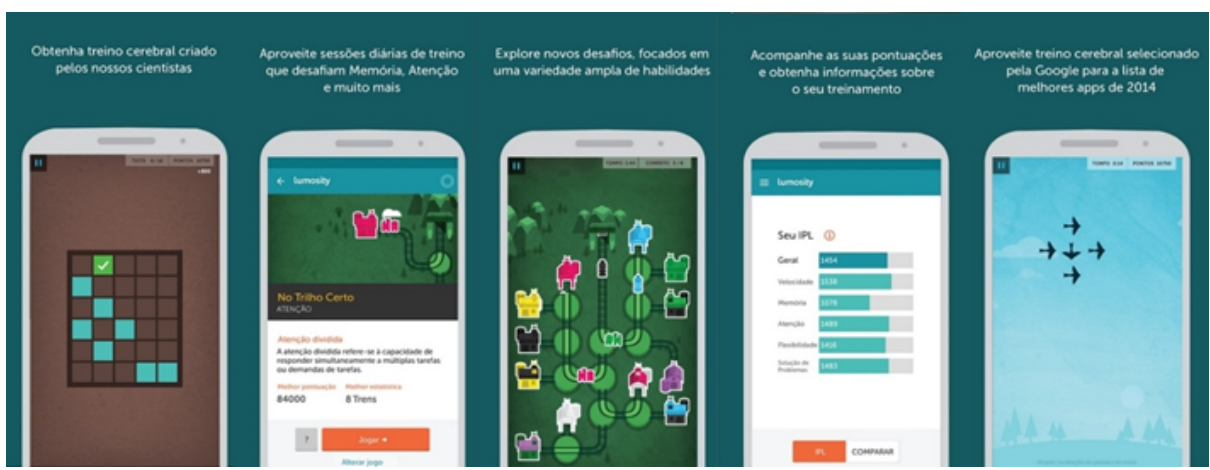

Fonte: Elaborada pelo próprio autor, a partir de busca na Google Play Store. 
Projética, Londrina, v.11, n.1, p. 37-59, abril 2020

Ao ressaltar a ideia de "treino cerebral" observamos o diálogo entre a proposta do Lumosity e a perspectiva de Csikszentmihalyi e Nakamura (2014) da criatividade como um conjunto de habilidades cognitivas relacionadas a personalidade, e ainda a proposta de Alencar e Fleith (2003) da ocorrência do ato criativo ser favorecido em pessoas que possuem domínio de técnicas existentes.

As críticas negativas apresentadas pelos usuários do Lumosity-Treinamento Cerebral se referem aos valores de compras pelos serviços adicionais, cobrança dos valores em dólar e limitação de funções para usuários que optam pela versão gratuita do aplicativo.

Figura 5 - Tee: Inspiração \& Criatividade

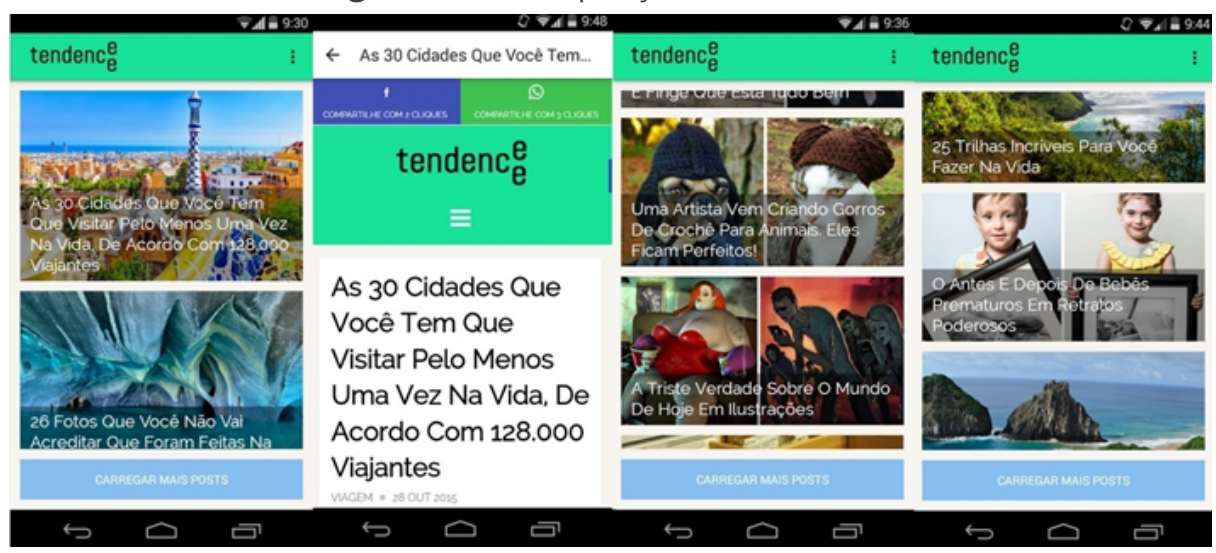

Fonte: Elaborada pelo próprio autor, a partir de busca na Google Play Store.

Em seguida, verificou-se o aplicativo Tee: Inspiração \& Criatividade (figura 05). Em referência ao nome Tendencee, o app apresenta-se como um blog de inspiração e criatividade a partir de uma perspectiva mais positiva da relação humana com a criatividade, evidenciando a tese da criatividade como resposta ao bem estar da humanidade, conforme apontou uma das propostas teóricas apresentadas neste artigo. “Hoje em dia é muito difícil ficar inspirado, criativo e principalmente, otimista 
[...] Assim, nosso conteúdo é bem curado para você ficar para cima e otimista com relação ao mundo", informa a descrição do Tee. As publicações são divididas nas categorias: arte, decoração, design, inovação, viagem e histórias.

O aplicativo apresenta boas avaliações dos usuários: “Ótimo trabalho! Parabéns! O app está sensacional!", avaliou a usuária 09. “Excelente! Pequeno, fácil e rápido" complementa o usuário 10.

Figura 6 - Pinterest - D/Y \& Craft

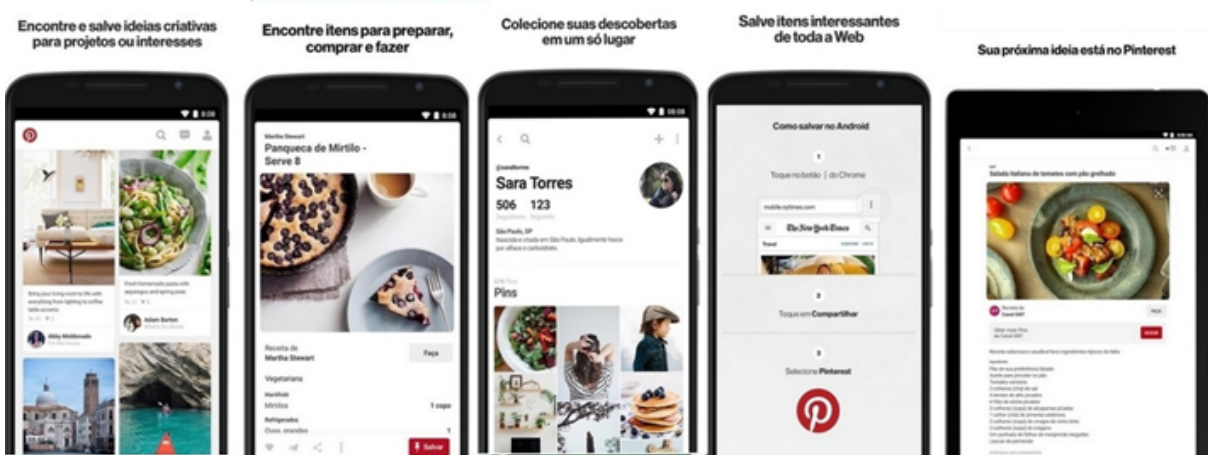

Fonte: Elaborada pelo próprio autor, a partir de busca na Google Play Store.

O último aplicativo avaliado neste estudo foi o Pinterest - DIY \& Craft (figura 06). Este se apresenta como um catálogo de ideias que possibilita o armazenamento de conteúdos e compartilhamento destes com outros usuários. Assim como o Creative Ideas - DIY \& Craft, o Pinterest - DIY \& Craft apresenta funções e interface semelhante aos de redes sociais mais populares no Brasil, diferenciando-se destas pelo interesse comum na utilização do serviço: a busca por inspirações e referências criativas.

O aplicativo oferece conteúdos relacionados a truques de organização, decoração, fitness, receitas, moda, frases, referências em design, arte, tatuagens 
Projética, Londrina, v.11, n.1, p. 37-59, abril 2020

e conteúdos relacionados à organização de festas e casamentos (vestidos, decoração, convites). Para torná-lo mais rápido, o app oferece atualizações a cada duas semanas e disponibiliza um canal de contato para usuários emitirem opiniões sobre as versões mais recentes.

As resenhas publicadas pelos usuários do Pinterest - D/Y \& Craft ressaltam a possibilidade de organização de referências com a utilização de pastas, conforme descreve a usuária 11: “Nesse aplicativo tenho acesso a muitos conteúdos de qualidade em um lugar só. Além de poder formar pastas com assuntos que mais gosto". A opinião é compartilhada pela usuária, 12: "Gosto de me inspirar e ver coisas lindas pelo mundo e no Pinterest posso montar meus álbuns com vários assuntos e consultar sempre que precisar."

Outros usuários destacam a variedade de conteúdos no app: “Nunca vi algo como isso, são tantas ideias fantásticas, aprendi muita coisa e aprendo a cada dia! Parabéns" comenta o usuário 13. Opinião semelhante à apresentada pela usuária 14: “O Pinterest é maravilhoso! Fotos de todo o mundo, paisagens, arte, tudo que nós adoramos ver. Parabéns! Recomendo a todos que amam o belo!".

A resenha da usuária 15 ressalta a utilização do aplicativo em seu trabalho: "Gosto muito do aplicativo, tem me ajudado muito. Sou artesã, o app ajuda muito a criar novas ideias". O usuário 16 descreve: "É uma vastidão de imagens de bom gosto. Encontro sites com apresentação e informação. Sou atendido com plenitude. Posso ilustrar qualquer coisa com uma boa imagem fácil de encontrar. Bom!".

As críticas ao Pinterest - DIY \& Craft, devem-se as modificações de interface após as atualizações, como alterações em tamanhos de fontes, retirada de ícones e opiniões sobre o layout do serviço após lançamento de novas versões. 


\section{CONSIDERAÇÕES FINAIS}

Em concordância com considerações realizadas ao longo deste artigo, acreditamos que os processos criativos encontram o devido respalado entre as propostas desenvolvidas por cada aplicativo e a usabilidade aplicada as necessidades de cada usuário.

A oferta de serviços existentes na loja de aplicativo digitais utilizada neste estudo, a Google Play Store, bem como a interação dos usuários coloca em evidencia a dimensão dos processos criativos contemplados por meio das opiniões, sugestões de melhorias e compartilhamento de experiências criativas que foram possibilitadas a partir da utilização dos aplicativos pesquisados.

A própria variabilidade na categorização de aplicativos na busca por "Criatividade" enuncia a devida dimensão do conceito ao relacioná-lo com estilo de vida, entretenimento, educação, notícias, e social - o que evidencia o processo criativo enquanto ato passível de constante modificação e presente em qualquer perfil de usuário.

Trata-se de uma tendência delineada pela própria Ergonomia ao estruturar-se com o agrupamento de diferentes correntes teóricas para tornar-se uma disciplina que proporciona o estabelecimento de conexões entre atividades laborais e do cotidiano, resultando na otimização dos mais variados processos que caracterizam as atividades humanas. Neste sentido, Klafke, Pissetti e Vieira (2013, p. 7) afirmam que de um sentido inicial entre homem e trabalho, a Ergonomia transformou-se para toda a interação do homem com objetos e elementos utilizados em atividades, resultado que foi possível a partir de uma amplificação de seu conceito original. 
Projética, Londrina, v.11, n.1, p. 37-59, abril 2020

Contribuindo tais ideias, este artigo corrobora com o estudo das tecnologias digitais que crescem a partir da inserção destes recursos em contextos de trabalho, educação, saúde e no dia a dia dos seus usuários, refutando as perspectivas aqui estudadas para maior compreensão da criatividade e dos processos criativos. 


\section{REFERÊNCIAS}

1. ALENCAR, Eunice M. L. Soriano; FLEITH, Denise Souza. Criatividade: múltiplas perspectivas. Brasília: Editora UnB, 2003.

2. ANDRIOLI, Mary Grace Pereira; VIEIRA, Claudia Regina; CAMPOS, Sandra RL. Uso das tecnologias digitais pelas pessoas surdas como um meio de ampliação da cidadania. In: ENCONTRO DA ASSOCIAÇÃO BRASILEIRA DE PESQUISADORES EM EDUCAÇÃO ESPECIAL, 7., 2013. Londrina. Anais [...]. Londrina: UEL, 2013. v. 5.

3. BRAGA, Alexandre. Interface: sistema orientado à visualização. Revista GEMInIS, São Paulo, v. 6, n. 1 p. 125-140, 2015.

4. CAIVANO, Simone; FERREIRA, Beatriz Jansen; DOMENE, Semíramis Martins Álvares. Avaliação da usabilidade do guia alimentar digital móvel segundo a percepção dos usuários. Ciência \& Saúde Coletiva, Rio de Janeiro, v. 19, n. 5, p. 1437-1446, 2014.

5. COELHO, Luiz Antonio. Conceitos chave em desing. Rio de Janeiro: Editora PUC - Rio, 2008.

6. CORRADI, Juliane Adne Mesa; VIDOTTI, Silvana Aparecida Borsetti Gregorio. Ambientes informacionais digitais acessíveis a minorias lingüísticas surdas: cidadania e/ou responsabilidade social. In: ENCONTRO NACIONAL DE PESQUISA EM CIÊNCIA DA INFORMAÇÃO, 10., 2009, João Pessoa, PB. Anais [...]. João Pessoa: ANCIB, 2009. Disponível em: http://enancib.ibict.br/index.php/ enancib/xenancib/schedConf/presentations. Acesso em: 5 out. 2016.

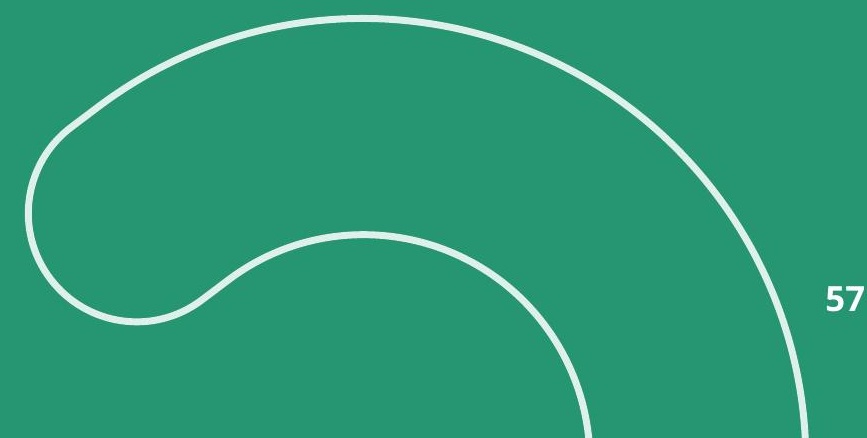


Projética, Londrina, v.11, n.1, p. 37-59, abril 2020

7. CSIKSZENTMIHALYI, Mihaly; NAKAMURA, Jeanne. Creativity and responsibility. In: CSIKSZENTMIHALYI, Mihaly. The systems model of creativity: the collected works of Mihaly Csikszentmihalyi. Netherlands: Springer, 2014. p. 279-292.

8. DE MASI, Domenico. Criatividade e grupos criativos. Rio de Janeiro: Sextante, 2003.

9. DEJOURS, Christophe; BÈGUE, Florence. Suicídio e trabalho: o que fazer. Brasília: Paralelo, 2010. v. 15.

10. GIL, Antônio Carlos. Como elaborar projetos de pesquisa. São Paulo: Atlas, 2002.

11. IIDA, Itiro. Ergonomia: projeto e produção. São Paulo: Edgard Blücher, 1997.

12. KLAFKE, Paulo Alberto; PISSETTI, Rodrigo Fernandes; VIEIRA, Gabriel Bergmann Borges (org.). Análise ergonômica: ergonomia aplicada ao design. Caxias do Sul: Livros Digitais FSG, 2013. v. 1.

13. LÉVY, Pierre. Cibercultura. Tradução de Carlos Irineu da Costa. São Paulo: Editora 34, 1999.

14. MORAES, Douglas Alves; PISA, Ivan Torres; LOPES, Paulo Roberto Lima. Protótipo para coleta de informações em saúde utilizando dispositivos móveis. In: CONGRESSO BRASILEIRO DE INFORMATICA EM SAÚDE, 9., 2004, Ribeirão Preto. Anais [...]. Ribeirão Preto, 2004. p. 1-4.

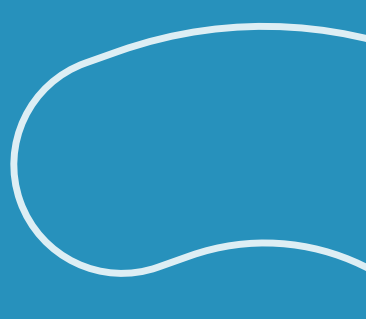


15. NÚMERO de smartphones em uso no Brasil chega a 168 milhões, diz estudo. Folha de São Paulo, São Paulo, 15 maio 2016. Disponível em: http://www1.foIha.uol.com.br/mercado/2016/04/1761310-numero-de-smartphones-em-uso-no-brasil-chega-a-168-milhoes-diz-estudo.shtml. Acesso em: 5 out. 2016.

16. OIKAWA, Erika. Os paradoxos hipermodernos e as tecnologias digitais: reflexões sobre a sociabilidade contemporânea a partir das práticas de "bem-estar". Sessões do Imaginário, Porto Alegre, v. 18, n. 30, p. 89-96, 2014.

17. OLIVEIRA, Thiago Robis; COSTA, Francielly Morais Rodrigues. Desenvolvimento de aplicativo móvel de referência sobre vacinação no Brasil. Journal of Health Informatics, São Paulo, v. 4, n. 1, p. 23-27, 2012.

18. OSTROWER, Fayga. Criatividade e processos de criação. Rio de Janeiro: Editora Vozes, 1978.

19. TORQUATO, Mirian; WILLERDING, Inara; LAPOLLI, Edis Mafra. A contribuição da criatividade para o processo de inovação: contribuições da criatividade em diversas áreas do conhecimento. São Paulo: Pimenta Cultura, 2013.

20. VAN DER LINDEN, J. C. S. Ergonomia e design: prazer, conforto e risco no uso de produtos. Porto Alegre: Ed. UniRitter, 2007.

21. WALZ, Alex. Deconstructing the app store rankings formula with a little mad science. 2015. In: Blog Moz. Seattle, WA, 27 May 2015. Disponível em: https:// moz.com/blog/app-store-rankings-formula-deconstructed-in-5-mad-science-experiments?utm_source=RankMyApp. Acesso em: 1 set. 2016. 